

\title{
World Total Factor Productivity Growth and the Steady-State Rate in the $20^{\text {th }}$ Century
}

\author{
Theodore R. Breton* \\ Universidad EAFIT
}

March 2, 2013

\begin{abstract}
I estimate a Solow model augmented with human capital in 42 countries for 1910-2000. Estimated TFP growth is 0.3\%/year, and the steady-state rate for GDP/capita is $1.0 \% / y e a r$. Implicitly for high-income countries maintaining growth above this rate will be increasingly difficult.
\end{abstract}

JEL Codes: O41; O47

Key Words: Economic Growth, Solow Model, Steady State, TFP Growth, Convergence *Theodore R. Breton, Universidad EAFIT, Carrera 49\#7 Sur-50, avenida Las Vegas, Medellin, Colombia ted.breton@gmail.com and tbreton@eafit.edu.co 574-250-5322 (home) 574-261-9334 (office) 574-261-9294 (fax) 


\section{Introduction}

There is growing evidence that the Solow model augmented with human capital provides a good representation of the economic growth process [Krueger and Lindahl, 2001, Cohen and Soto, 2007, and Breton, 2012/2013]. In this model GDP (Y) changes over time (t) in response to changes in physical capital $(\mathrm{K})$, human capital $(\mathrm{H})$, labor $(\mathrm{L})$, and total factor productivity (A): 1) $\quad Y_{t}=K_{t}^{\alpha} H_{t}^{\beta}\left(A_{t} L_{t}\right)^{1-\alpha-\beta}$

The augmented Solow model predicts that with constant shares of GDP invested in physical and human capital, economic growth converges to the steady-state rate of technological growth. Across the developed world economic growth has slowed dramatically and shows little sign of acceleration. Is it possible that growth in the most developed countries has converged to the steady state?

In this paper I estimate the parameters of the augmented Solow model using data for 1910 and 2000 in 42 countries to determine the average rate of TFP growth and the steady-state rate of growth during the twentieth century. I find that annual TFP growth was $0.3 \%$ and that the steady-state rate was approximately $1 \% /$ year. The implication is that the most developed countries will find it increasingly difficult to maintain economic growth above $1 \% / y e a r$.

The paper is organized as follows: Section II presents the methodology. Section III presents the results. Section IV concludes.

\section{Methodology}

In the augmented Solow model, the effect of new technology and more efficient management practices on TFP is the residual after accounting for the effect of increases in physical capital and human capital. The residual tends to be overestimated because the 
measurement error in the human capital data creates attenuation bias in OLS estimates of the effect of human capital on GDP [Krueger and Lindahl, 2001].

In this study I limit this bias by measuring human capital with improved cross-country data on average schooling attainment from Morrisson and Murtin [2009], by estimating the effect of changes in attainment over a very long period, and by using an instrument for human capital. I estimate the augmented Solow model using data for 1910 and 2000. I use these two years for several reasons. First, these years have the most accurate schooling data before and after the world wars. Second, data for the Protestant share of the population are available to serve as an instrument for schooling in these two years. Third, these two years each follow twenty-year periods of high global financial capital mobility during which investment capital was widely available across countries [Obstfeld and Taylor, 2004]. Under these conditions physical capital is endogenous, which makes it possible to estimate the effect of changes in human capital and physical capital in the augmented Solow model using human capital alone. This is crucial because data for GDP/capita and human capital are available for 1910, but data for physical capital are not.

In the augmented Solow model, the marginal product of physical capital (MPK) is:

$$
\mathrm{MPK}=\delta \mathrm{Y} / \delta \mathrm{K}=\alpha(\mathrm{K} / \mathrm{L})^{\alpha-1}(\mathrm{H} / \mathrm{L})^{\beta} \mathrm{A}^{1-\alpha-\beta}
$$

Solving for $\mathrm{K} / \mathrm{L}$ and substituting this relationship into equation (1) yields:

$$
(\mathrm{Y} / \mathrm{L})_{\mathrm{t}}=\left(\alpha / \mathrm{MPK}_{\mathrm{t}}\right)^{\alpha / 1-\alpha}(\mathrm{H} / \mathrm{L})_{\mathrm{t}}^{\beta / 1-\alpha} \mathrm{A}_{\mathrm{t}}^{(1-\alpha-\beta) /(1-\alpha)}
$$

In a global capital market, the financial return on investment is the same across countries (i), so the MPK of physical capital at an international price can be estimated as a function of this return (rk) and the relative domestic price of this capital $(\mathrm{Pk})$ :

$$
\mathrm{MPK}_{\mathrm{it}} \approx \mathrm{kPk}_{\mathrm{it}}{ }^{\gamma} \mathrm{rk}_{\mathrm{t}}
$$


where $\gamma$ depends on the working life of physical capital.

In cross-country estimation of the Solow model, MPK is the value after adjusting prices for purchasing power, which raises Pk in the lower-income countries. Hsieh and Klenow [2007] show that these higher adjusted prices are almost entirely the result of the low productivity in the production of investment goods and tradable consumer goods. Since the technology available for physical capital is similar across countries with market economies, this lower productivity is due primarily to the lower level of human capital in the lower-income countries. As a consequence:

5) $\quad \mathrm{Pk}_{\mathrm{it}}=\mathrm{c}(\mathrm{H} / \mathrm{L})_{\mathrm{it}}^{-\theta}$, where $\theta>0$.

Substituting equations (4) and (5) into equation (3), assuming a constant return on global financial capital over time, and specifying $A_{t}=A_{0} e^{g t}$ yields:

6) $\quad(\mathrm{Y} / \mathrm{L})_{\mathrm{it}}=\left(\alpha \mathrm{c}^{\theta \gamma / \mathrm{k} \mathrm{rk}}\right)^{\alpha / 1-\alpha}\left(\mathrm{A}_{0} \mathrm{e}\right)^{\mathrm{g}((1-\alpha-\beta) /(1-\alpha)) \mathrm{t}}\left(\mathrm{H} / \mathrm{L}_{\mathrm{it}}\right)^{(\gamma \theta+(\beta / 1-\alpha))}$

Implicitly human capital in the Solow model is measured in the same way as physical capital, as a net financial stock calculated from historic rates of investment and depreciation. The model in equation (6) is formally a model of GDP/worker, but it is frequently estimated using GDP/capita and human capital/adult.

In cross-country analyses the average years of schooling attainment of the population between ages 15 and 64 is commonly used as the proxy for human capital/adult $(\mathrm{H} / \mathrm{L})$. Breton [2012/2013] estimates the net financial stock of human capital in 61 countries and shows that the relationship between these stocks of human capital and Cohen and Soto's estimates of average schooling attainment (attain) was log-linear in 1990:

7) $\quad \log (\mathrm{H} / \mathrm{L})=\mathrm{a}+0.32$ (attain) 
Since Morrisson and Murtin's data are very similar to Cohen and Soto's data, this relationship is valid for their data.

Converting equation (6) to log form and substituting equation (7) into this equation yields:

8) $\quad \log (\mathrm{Y} / \mathrm{L})_{\mathrm{it}}=\mathrm{c}_{0}+((1-\alpha-\beta) \mathrm{g} /(1-\alpha)) \mathrm{t}+0.32(\theta \gamma+(\beta / 1-\alpha))$ attain $_{\mathrm{it}}+\varepsilon_{\mathrm{it}}$

This equation shows that in a global financial market, average schooling attainment is a proxy for a nation's total capital stock.

In this equation $\alpha$ and $\beta$ are not identified, but their values are required to validate the augmented Solow model and to estimate the value of g over the 1910-2000 period. I estimate the implied values of $\alpha$ and $\beta$ by estimating a standard reduced form of equation (1) in 2000 that utilizes the relationship for $\log (\mathrm{H} / \mathrm{L})$ in equation (7):

9) $\quad \log (\mathrm{Y} / \mathrm{L})_{\mathrm{i}}=\mathrm{c}_{1}+\alpha /(1-\alpha) \log (\mathrm{K} / \mathrm{Y})_{\mathrm{i}}+(0.32 \beta) /(1-\alpha)$ attain $_{\mathrm{i}}+\varepsilon_{\mathrm{i}}$

I then calculate the values of $\alpha$ and $\beta$ from the estimated coefficients in this model.

Maddisson [2003] provides GDP/capita data for 1910 and 2000, but he does not provide data for physical capital investment. ${ }^{1}$ Therefore, I estimate equation (9) using data for 2000 from Penn World Table (PWT) 6.3 [Heston, Summers, and Aten, 2009] and match these results to results using Maddison's data. ${ }^{2}$ I do this by first estimating the effect of average attainment alone in equation (8) with PWT 6.3 data and then showing that the PWT 6.3 data and the Maddisson data yield the same estimates of the effect of average schooling attainment in 2000. I then use Maddisson's data for the 1910-2000 analysis.

\footnotetext{
${ }^{1}$ I use data for 1913 for a few countries that lack data for 1910.

${ }^{2}$ I use the rgdpch and ki data series and estimate the capital stocks using the perpetual inventory method, investment for 1960-99 and a geometric depreciation rate of 0.06. I use data from PWT 6.3 rather than from PWT 7.0 because the PWT 6.3 data appear to be more reliable [Breton, 2012]
} 
Figure 1 shows the relationship between Maddison's GDP/capita data and average schooling attainment for the 42 countries in 2000 . The sample is limited by the data availability in the various sources and by the requirement that countries have some Protestant affiliation during the estimation period, but the sample has sufficient variation to provide good results.

\section{Figure 1}

\section{GDP/capita vs. Average Schooling Attainment in 2000}

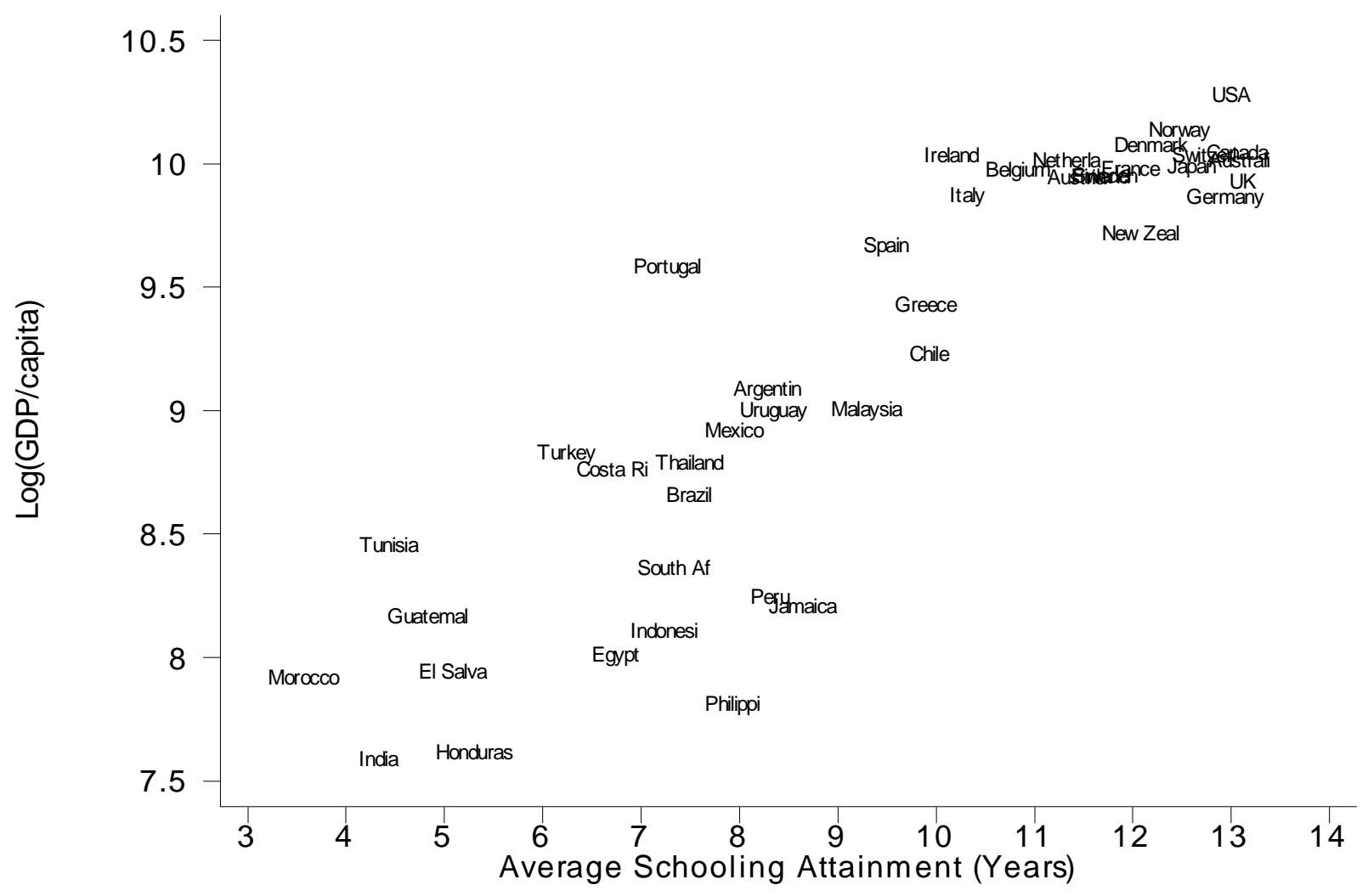

Since schooling attainment is endogenous, valid estimates of TFP growth and the steadystate rate require 2 SLS estimates of the effect of average attainment on GDP/capita. The validity of these estimates depends on the validity of a nation's share of Protestant affiliation as an instrument for schooling. I believe this characteristic is a valid instrument because, as 
documented in Breton [2012/2013], it has been correlated with levels of literacy and schooling across and within countries for centuries, changes in Protestant affiliation are not endogenous in the growth process, and hypotheses that Protestant affiliation affects national income other than through schooling (e.g., through the work ethic) have been consistently rejected. I use Barrett's [1982] data for Protestant affiliation ("professing Protestants") in 1900 and 1980 as the instrument for schooling in 1910 and 2000.

\section{Model Results}

Table 1 presents the empirical results for the two models in 2000. The first five columns present the results using the PWT 6.3 data. In column 1 the estimated coefficients using OLS for the full model are unacceptable because the coefficient on $\log (\mathrm{K} / \mathrm{Y})$ is insignificant and the implied value of $\alpha(0.24)$ is too low. In a valid Solow model, $\alpha$ is the share of national income accruing to physical capital, which averages about 0.35 across countries [Bernanke and Gurkaynak, 2001].

\section{Table 1}

Effect of Average Schooling Attainment on National Income in 2000 [Dependent Variable is $\log (\mathrm{GDP} / \mathrm{Capita})$

\begin{tabular}{|l|c|c|c|c|c|c|c|}
\hline & $\mathbf{1}$ & $\mathbf{2}$ & $\mathbf{3}$ & $\mathbf{4}$ & $\mathbf{5}$ & $\mathbf{6}$ & $\mathbf{7}$ \\
\hline Technique & OLS & 2SLS & OLS & 2SLS & OLS & 2SLS & OLS \\
\hline Countries & 42 & 42 & 42 & 42 & 42 & 42 & 42 \\
\hline Economic Data & PWT 6.3 & PWT 6.3 & PWT 6.3 & PWT 6.3 & Maddison & Maddison & Maddison \\
\hline Log(K/Y) & 0.32 & 0.67 & 0.67 & & & & \\
& $(.21)$ & $(.29)$ & $(.28)$ & & & & \\
\hline Attainment & $0.23^{*}$ & $0.16^{*}$ & $0.27^{*}$ & $0.19^{*}$ & $0.27^{*}$ & $0.19^{*}$ & $0.31^{*}$ \\
& $(.02)$ & $(.04)$ & $(.03)$ & $(.03)$ & $(.02)$ & $(.03)$ & $(.02)$ \\
\hline Estimated & & & $-0.10^{*}$ & & & & $-0.18^{*}$ \\
Attainment & .80 & .76 & .82 & .75 & .80 & .72 & $.83)$ \\
\hline $\mathrm{R}^{2}$ & .24 & .40 & & & & & \\
\hline Implied $\alpha$ & .55 & .31 & & & & & \\
\hline Implied $\beta$ & & & & & & \\
\hline Note: Robust standard errors in parentheses \\
$*$ Significant at one percent level
\end{tabular}


In column 2 the results using 2 SLS for the same model are acceptable and statistically significant. The implied values of $\alpha=0.40$ and $\beta=0.31$ are consistent with Cohen and Soto's [2007] and Breton's [2012/2013] results. Column 3 presents the results of a Hausman test, which rejects the hypothesis that the OLS estimates are unbiased. ${ }^{3}$

Column 4 presents the 2SLS results for the model with schooling attainment alone. As expected, the effect of schooling is larger ( 0.19 vs. 0.16$)$ than in the complete model. Since the explained variation in national income is similar in the complete model and in the model with schooling alone ( $75 \%$ vs. $76 \%$ ), these results confirm that changes in schooling attainment can represent both the change in human capital and the endogenous change in physical capital.

Column 6 shows that the 2SLS estimates of the effect of schooling attainment using Maddison's GDP data are the same as the 2SLS estimates using GDP data from PWT 6.3. This result provides confidence that the estimate of $1-\alpha-\beta$ using the PWT 6.3 data is applicable to the results using Maddison's data. Column 7 shows a Hausman test that rejects the hypothesis that the OLS estimates in 2000 using Maddison's data are unbiased.

Table 2 examines the effect of schooling on GDP in 1910 and over the 1910-2000 period using Maddison's data for GDP/capita in the model with schooling attainment alone. The 2SLS estimates are based on data for 29 countries in 2010, since 13 countries did not have any Protestant affiliation at that time. The results show that the effect of schooling attainment using OLS and 2SLS are very similar, and the Hausman test in column 3 shows that the OLS estimates are unbiased. These estimates of the effect of schooling in 1910 are remarkably similar to the 2SLS results in 2000 (0.17-0.19 vs. 0.19), which facilitates the analysis of the effect over time.

\footnotetext{
${ }^{3}$ The first stage results for the various 2 SLS estimations are not shown due to space limitations, but they are uniformly acceptable.
} 


\begin{tabular}{|c|c|c|c|c|c|c|c|c|}
\hline \multicolumn{9}{|c|}{$\begin{array}{c}\text { Table } 2 \\
\text { Effect of Average Schooling Attainment on National Income in } 1910 \text { and 1910-2000 } \\
\text { [Dependent Variable is Log(GDP/Capita)] }\end{array}$} \\
\hline & \multicolumn{3}{|c|}{1910} & \multicolumn{5}{|c|}{$1910-2000$} \\
\hline & 1 & 2 & 3 & 4 & 5 & 6 & 7 & 8 \\
\hline Sample Size & 29 & 29 & 29 & 84 & 71 & 71 & 58 & 84 \\
\hline Countries & 29 & 29 & 29 & 42 & 42 & 42 & 29 & 42 \\
\hline Technique & OLS & $2 \mathrm{SLS}$ & OLS & OLS & 2 SLS & OLS & 2 SLS & OLS/FE \\
\hline Attainment & $\begin{array}{l}0.19^{*} \\
(.03)\end{array}$ & $\begin{array}{l}0.17^{*} \\
(.05)\end{array}$ & $\begin{array}{l}0.20^{*} \\
(.04)\end{array}$ & $\begin{array}{l}0.24 * \\
(.01)\end{array}$ & $\begin{array}{l}0.18^{*} \\
(.03)\end{array}$ & $\begin{array}{l}0.27 * \\
.02)\end{array}$ & $\begin{array}{l}0.19^{*} \\
(.04)\end{array}$ & $\begin{array}{l}0.14^{*} \\
(.05)\end{array}$ \\
\hline $\begin{array}{l}\text { Estimated } \\
\text { Attainment }\end{array}$ & & & $\begin{array}{l}-0.03 \\
(.07)\end{array}$ & & & $\begin{array}{l}-0.09 \\
(.04)\end{array}$ & & \\
\hline Year & & & & $\begin{array}{l}0.002 \\
(.001)\end{array}$ & $\begin{array}{l}0.005 \\
(.002)\end{array}$ & $\begin{array}{l}0.005 \\
(.002)\end{array}$ & $\begin{array}{l}0.006 \\
(.003)\end{array}$ & $\begin{array}{c}0.009^{*} \\
(.003)\end{array}$ \\
\hline $\mathrm{R}^{2}$ & .59 & .60 & .72 & .88 & .82 & .85 & .87 & .96 \\
\hline Implied $\mathrm{g}$ & & & & & .010 & & .011 & \\
\hline Annual $\Delta$ TFP & & & & & $0.3 \%$ & & $0.3 \%$ & \\
\hline
\end{tabular}

Columns 4-8 present the results for the model with schooling attainment alone when it is estimated for the period 1910-2000. The OLS and 2SLS estimates are very different, and the Hausman test in column 6 rejects the hypothesis that the OLS results for 1910-2000 are unbiased. Two sets of 2SLS results are shown, one with an unbalanced panel, and one with a balanced panel of 29 countries. The unbalanced panel provides a more statistically-significant estimate of annual growth in TFP over the 90 years. The implied estimate of $[(1-\alpha-\beta) g]$ is 0.3 percent per year. Since $(1-\alpha) /(1-\alpha-\beta)=2.0$ in 2000 , the implied value of $g=2(0.005)=0.01$.

Column 8 presents an OLS estimate of the effect of schooling attainment on GDP/capita that includes country-specific fixed effects. The effect of schooling is smaller (0.14 vs. 0.18$)$ than in the 2SLS results. These results provide assurance that the positive effect of schooling is not due to omitted variables. The 2SLS estimate is likely to be more accurate because 
measurement error causes attenuation bias in OLS estimates, and the error is exacerbated when fixed effects are used in the estimation [Krueger and Lindahl, 2001].

The estimated rate of TFP growth in this study, $0.3 \% / y e a r$, is lower than in many other studies. Since this rate is a residual, it depends on the estimates of the effects of physical capital ( $\alpha$ ) and human capital ( $\beta$ ) on GDP. The value of $\alpha$ has been widely accepted as approximately 0.35, the share of GDP typically accruing to physical capital. But since the share of GDP accruing to human capital is part of the total share accruing to workers, the share accruing to human capital is not easily identified.

If the effect of human capital on GDP is limited to the increase in workers' salaries, then the estimate of $\beta$ is relatively small and the residual rate of TFP growth is relatively large. ${ }^{4}$ In this study the econometric estimate of $\beta$ is much larger than the effect of schooling on workers' salaries, which implies that human capital had large external effects on national income during the 1910-2000 period.

Breton [2012/2013] shows that due to the mathematical structure of the augmented Solow model, each factor of production has an external effect on the marginal product of the other factors of production. He also shows that once these external effects are taken into account, the relatively large estimated effect of human capital on GDP in this study $(\beta=0.31)$ is consistent with existing national estimates of the effect of increased schooling on workers' salaries.

\section{Conclusions}

The empirical results in this paper demonstrate that the augmented Solow model can explain the changes in GDP across countries during the $20^{\text {th }}$ century. Between 1910 and 2000 average GDP/capita in the data set increased by $1.9 \%$ /year. The model's estimates of the causes

\footnotetext{
${ }^{4}$ Madsen [2010] estimates TFP growth using this method and obtains a larger rate than this study for the same time period.
} 
of this growth indicate that the annual increase in total factor productivity was $0.3 \%$, while $1.6 \%$ was due to factor accumulation. Since these results indicate that the steady-state rate of growth was only $1.0 \% / y e a r$, the other $0.9 \%$ /year was implicitly a temporary growth effect related to the rising average share of GDP devoted to investment over the course of the century.

Looking forward, the rate of world technological growth (g) could increase, and countries can continue to raise the share of GDP they invest in physical and human capital. But in the Solow model the marginal product of capital is subject to decreasing returns, which makes the return on incremental investment less and less attractive. Ultimately in this model the steadystate rate is the ceiling on the annual rate of growth. These empirical results suggest that in developed countries that already allocate a high share of GDP to investment (e.g., Japan), GDP/capita growth of about $1 \% /$ year is likely to become the norm rather than the exception. 


\section{ACKNOWLEDGEMENTS}

I am grateful to Andrew Breton and to an anonymous referee who provided helpful comments on earlier drafts of this paper.

\section{REFERENCES}

Barrett, David B., 1982, The World Christian Encyclopedia, Oxford University Press, New York Bernanke, Ben S., and Gurkaynak, Refet S., 2001, “Taking Mankiw, Romer, and Weil Seriously,” NBER Macroeconomics Annual, v16, 11-57

Breton, Theodore R., 2012/2013, “Were Mankiw, Romer, and Weil Right? A Reconcilation of the Micro and Macro Effects of Schooling on Income" Macroeconomic Dynamics, v17, n5, forthcoming in 2013, published online March 19, 2012

Breton, Theodore R., 2012, “Penn World Table 7.0: Are the Data Flawed?” Economics Letters, $117,208-210$

Cohen, Daniel, and Soto, Marcelo, 2007, "Growth and Human Capital: Good Data, Good Results," Journal of Economic Growth, v12, n1, 51-76

Heston, Alan, Summers, Robert, and Aten, Bettina, 2009, Penn World Table Version 6.3, Center for International Comparisons of Production, Income and Prices at the University of Pennsylvania (CICUP)

Hsieh, Chang-Tai, and Klenow, Peter J., 2007, "Relative Prices and Relative Prosperity," American Economic Review, v97, n3, 562-585

Krueger, Alan B., and Lindahl, Mikael, 2001, "Education for Growth: Why and For Whom?," Journal of Economic Literature, v39, 1101-1136 
Maddison, Angus, 2003, The World Economy: Historical Statistics, Development Centre of the Organisation for Economic Co-operation and Development, Paris, France

Madsen, Jakob B., 2010, “The Anatomy of Growth in the OECD Since 1870,” Journal of

Monetary Economics, 57, 753-767

Morrisson, Christian, and Murtin, Fabrice, 2009, “The Century of Education,” Journal of Human

Capital, v3, n1, 1-42

Obstfeld, Maurice, and Taylor, Alan, 2004, Global Capital Markets: Integration, Crisis, and Growth, Cambridge University Press, Cambridge 